\title{
Erratum to: Manipulability agreement as a predictor of action initiation latency
}

\author{
Katherine Guérard $^{1} \cdot$ Mathieu B. Brodeur ${ }^{2}$
}

Published online: 7 January 2016

(C) Psychonomic Society, Inc. 2016

Erratum to: Behav Res Volume 47, Issue 2, pp. 572-579

DOI 10.3758/s13428-014-0495-6

ESM 1 contains an error. The standard deviations for the initiation times of the first 51 objects were incorrect. The correct ESM is attached.

The online version of the original article can be found at http://dx.doi.org/ 10.3758/s13428-014-0495-6.

Electronic supplementary material The online version of this article (doi:10.3758/s13428-015-0699-4) contains supplementary material, which is available to authorized users.

$\triangle$ Katherine Guérard

katherine.guerard@umoncton.ca

1 École de psychologie, Université de Moncton, Moncton, New Brunswick E1A 3E9, Canada

2 Douglas Mental Health University Institute and Department of Psychiatry, McGill University, Montreal, Quebec, Canada 